\title{
Erratum to: Response to L. Land Comment on Bricker, Rice, Bricker (2014) From Headwaters to Coast: Influence of Human Activities on Water Quality of the Potomac River Estuary. Aquatic Geochemistry 20: 291-324
}

\author{
Suzanne B. Bricker • Karen C. Rice • Owen P. Bricker III
}

Received: 11 July 2014/ Accepted: 11 July 2014/Published online: 23 July 2014

(C) Springer Science+Business Media Dordrecht 2014

\section{Erratum to: Aquat Geochem \\ DOI 10.1007/s10498-014-9233-z}

After the article has been published online first, it came clear that the authors have misquoted unpublished data and have partially mis-identified the affiliation.

The mis-quoted sentence (in the top half of pg 3 of 5) is as follows:

A recent study of Gulf of Mexico oyster shells shows that 820-2,500-year-old shell has a nitrogen content of $0.049 \pm 0.012 \%$ by weight, whereas modern oyster shells are $0.46 \pm 0.01 \%$ (Juvenile diploids), $0.26 \pm 0.01 \%$ (Adult) by weight (Dalrymple and Carmichael, University of South Alabama, unpublished data).

The corrected sentence (addition in bold) should read:

A recent study of Gulf of Mexico oyster shells shows that 820-2,500-year-old shell has a nitrogen content of $0.049 \pm 0.012 \%$ by weight (Darrow and Carmichael, Dauphin

The online version of the original article can be found under doi:10.1007/s10498-014-9233-z.

S. B. Bricker $(\square)$

Silver Spring, MD, USA

e-mail: Suzanne.Bricker@noaa.gov

K. C. Rice

Charlottesville, VA, USA

O. P. Bricker III

Reston, VA, USA 
Island Sea Lab \& University of South Alabama, unpublished data), whereas modern oyster shells are $0.46 \pm 0.01 \%$ (Juvenile diploids), $0.26 \pm 0.01 \%$ (Adult) by weight (Dalrymple and Carmichael, Dauphin Island Sea Lab \& University of South Alabama, unpublished data).

The affiliation in the acknowledgements (on pg 4 of 5) must also be corrected in the first line from: We thank Ruth Carmichael (University of South Alabama) for unpublished data.

to:

We thank Ruth Carmichael and her students (Dauphin Island Sea Lab \& University of South Alabama) for unpublished data. 